\title{
Response of the pigeonpea-Rhizobium symbiosis to salinity stress: Variation among Rhizobium strains in symbiotic ability *
}

\author{
G.V. Subbarao ${ }^{1}$, C. Johansen ${ }^{1}$, J.V.D.K. Kumar Rao ${ }^{1}$, and M.K. Jana ${ }^{2}$ \\ ${ }^{1}$ Legumes Program, International Crops Research Institute for the Semi-Arid Tropics (ICRISAT), Patancheru, A.P. 502 324, India \\ ${ }^{2}$ Department of Agricultural Engineering; Indian Institute of Technology, Kharagpur, West Bengal 721 302, India
}

Summary. There were significant differences among pigeonpea [Cajanus cajan (L.) Millsp] Rhizobium sp. strains (IC 3506, IC 3484, IC 3195, and IC 3087) in their ability to nodulate and fix $\mathrm{N}_{2}$ under saline conditions. Pigeonpea plants inoculated with IC 3087 and IC 3506 were less affected in growth by salinity levels of 6 and $8 \mathrm{dS} \mathrm{m}^{-1}$ than plants inoculated with the other strains. For IC 3506, IC 3484, and IC 3195, there was a decrease in the number of nodules with increasing salinity, while the average nodule dry weight and the specific nitrogenase activity remained unaffected. However, in IC 3087; the number of nodules increased slightly with increasing salinity. Leaf-P concentrations increased with salinity in the inoculated plants irrespective of the Rhizobium sp. strain, and leaf-N concentrations decreased with increasing salinity in IC 3484 and IC 3195 only. Shoot-Na and - $\mathrm{Cl}$ levels were further increased in these salt-sensitive strains only at $8 \mathrm{dS} \mathrm{m}^{-1}$. Therefore there may be scope for selecting pigeonpea Rhizobium sp. symbioses better adapted to saline conditions. The Rhizobium sp. strains best able to form effective symbioses at high salinity levels are not necessarily derived from saline soils.

Key words: Cajanus cajan - Pigeonpea - Rhizobium variation - Salinity stress - Symbiotic nitrogen fixation

Pigeonpea [Cajanus cajan (L.) Millsp] is one of the important grain legumes grown in semi-arid regions where salinity problems can be acute (Chauhan 1987). Since the agricultural importance of legumes is particularly related to their ability to fix $\mathrm{N}_{2}$ in root nodules,

\footnotetext{
* Submitted as JA No. 919 by the International Crops Research Institute for the Semi-Arid Tropics (ICRISAT)

Offprint requests to: $\mathrm{C}$. Johansen
}

any study on the feasibility of growing pigeonpea under saline conditions must include information on the effects of salinity on the pigeonpea-Rhizobium sp. symbiosis. Various reports have been published on salinity effects on the nodulation and $\mathrm{N}_{2}$ fixation of different legumes (Bernstein and Ogata 1966; Wilson 1970; Lakshmi-Kumari et al. 1974; Balasubramanian and Sinha 1976; Lauter et al. 1981; Yousef and Sprent 1983; Singleton and Bohlool 1984; Siddiqui et al. 1985 ) but only a single Rhizobium sp. strain was used in each study. There is wide variation among Rhizobium sp. strains in their ability to grow and survive under saline conditions in yeast extract mannitol agar medium (Singleton et al. 1982; Subbarao 1984); the extent of the variation in their symbiotic ability under saline conditions is still to be determined. In the present investigation, we attempted to measure this variation in the pigeonpea-Rhizobium sp. symbiosis.

\section{Materials and methods}

Rhizobium sp. strains and culture conditions. The Rhizobium sp. cultures used in the present study were obtained from the pigeonpea Rhizobium collection of the Legumes Program, ICRISAT, India. These were selected on the basis of their growth habit, tolerance to $\mathrm{NaCl}$ on yeast extract mannitol agar, and ecological origin (Table 1), and were all effective in fixing $\mathrm{N}_{2}$ in symbiosis with pigeonpea. All cultures were maintained on yeast extract mannitol agar slopes (Vincent 1970). A loopful of Rhizobium sp. culture was inoculated into the sterilized yeast extract mannitol broth and incubated at $28^{\circ} \mathrm{C}$ for 3 and 7 days for fast- and slow-growing strainis, respectively. After incubation, the culture was checked for purity by streaking a loopful of the broth culture on congo red yeast extract mannitol agar and incubating at $28^{\circ} \mathrm{C}$.

Plant culture. The growth medium consisted of sieved river sand, which was washed and soaked in acid solution ( $\mathrm{pH} \mathrm{1-2)} \mathrm{for} 24 \mathrm{~h}$, and then thoroughly washed with tap water, dried, and filled in $180 \mathrm{~mm}$ diameter plastic pots. The pots with sand were steamsterilized. Pigeonpea seeds of the salinity-tolerant genotype ICPL 227 were surface-sterilized with $0.2 \% \mathrm{HgCl}_{2}$ solution for $5 \mathrm{~min}$ and 
Table 1. Origin and growth characteristics and tolerance to $\mathrm{NaCl}$ salinity on yeast extract mannitol agar (YEMA) of pigeonpea $R h i$ zobium cultures used in the study

\begin{tabular}{|c|c|c|c|c|}
\hline Rhizobium & Strain origin & $\begin{array}{l}\text { Soil } \\
\text { isolated } \\
\text { from }\end{array}$ & $\begin{array}{l}\text { Growth } \\
\text { on } \\
\text { YEMA }\end{array}$ & $\begin{array}{l}\text { Tolerance } \\
\text { to } \mathrm{NaCl} \\
\text { on } \\
\text { YEMA } \\
\left(\mathrm{dS} \mathrm{m}^{-1}\right)\end{array}$ \\
\hline IC 3506 & Gujarat, India & Vertisol & Fast & 86.0 . \\
\hline IC 3484 & Maharastra, India & Vertisol & Slow & 34.2 \\
\hline IC 3087 & ICRISAT Center & $\begin{array}{l}\text { Vertisol } \\
\text { (saline) }\end{array}$ & Slow & 8.6 \\
\hline IC 3195 & ICRISAT Center & Alfisol & Slow & 4.3 \\
\hline
\end{tabular}

then washed with deionized water. Eight surface-sterilized seeds were sown in each pot. The sand surface in each pot was covered with $50 \mathrm{~g}$ of polythene beads in order to minimize evaporation, and the pots were supplied with sterilized deionized water. For all watering and flushing operations, the solutions were sterilized before use in order to avoid cross contamination. On the 10th day after sowing, the seedlings were thinned to four per pot. There were four salinity treatments, $0,4,6,8 \mathrm{dS} \mathrm{m}^{-1}$, and seven $\mathrm{N} /$ Rhizobium sp. treatments: (1) fed with inorganic N; (2) inoculated with Rhizobium sp. strain IC 3024 at the time of sowing (IC 3024 early); (3) inoculated with IC 302414 days after sowing (IC 3024 late); (4) IC 3506 late; (5) IC 3484 late; (6) IC 3087 late; and (7) IC 3195 late. The N-fed treatmient was given $50 \mathrm{mg} \mathrm{l}^{-1} . \mathrm{N}$ as $\mathrm{NH}_{4} \mathrm{NO}_{3}$ from 28 days after sowing. The results of the $\mathrm{N}$-fed, and the IC 3024 early and late treatments are being published separately.

A modified Arnon and Hoagland N-free nutrient solution (1:4 strength) amended with $\mathrm{NaCl}+\mathrm{CaCl}_{2}(1: 1 \mathrm{w}: \mathrm{w})$ was used for the various salinity treatments. The composition of the nutrient solution (full strength) in $m M$ was: $0.9 \mathrm{KH}_{2} \mathrm{PO}_{4}, 2.08 \mathrm{KCl}, 1.01 \mathrm{MgSO}_{4}$ $-7 \mathrm{H}_{2} \mathrm{O}, 1.46 \mathrm{CaCl}_{2} \cdot 2 \mathrm{H}_{2} \mathrm{O}, 0.006 \mathrm{MnSO}_{4} \cdot \mathrm{H}_{2} \mathrm{O}, 0.0009 \mathrm{ZnSO}_{4} \cdot 7 \mathrm{H}_{2} \mathrm{O}$, $0.001 \mathrm{CuSO}_{4} \cdot 5 \mathrm{H}_{2} \mathrm{O}, 0.004 \mathrm{H}_{3} \mathrm{BO}_{3}, 0.0002 \mathrm{Na}_{2} \mathrm{MoO}_{4} \cdot 2 \mathrm{H}_{2} \mathrm{O}, \quad 0.16$ NaFeEDTA. The electrical conductivity of the nutrient solution ( $1: 4$ strength) without any added salt was $0.33 \mathrm{dS} \mathrm{m}^{-1}$. The experi- ment was arranged in a randomized block design with four replications, in a greenhouse with a mean temperature of $28 / 22^{\circ} \mathrm{C}$ (day/night) and relative humidity of $60-70 \%$ (mean day + night).

The salinity treatments were imposed on the 14th day after sowing by flushing each pot with 11 treatment solution and the Rhizobium $\mathrm{sp}$. inoculation was done afterwards. For the no-salinity treatment (control), a 1:4 strength nutrient solution was used for all the flushing operations. One milliliter of broth containing approximately $10^{8}$ rhizobia was added per seedling and this was repeated after 3 days to ensure a sufficient Rhizobium sp. population in the pot. The pots were flushed with the treatment solutions $\left(0.251\right.$ pot $\left.^{-1}\right)$ once every 4 days to avoid salt build-up. At the end of every day, the evapotranspirational water losses were made up by adding sterile deionized water. The pots were rerandomized every 4 days to minimize spatial effects in the greenhouse.

On the 65 th day after sowing, the plants were harvested. The leaf area was measured with an automatic leaf-area meter (Delta T Devices Limited, England) and the nodulated roots were assayed for nitrogenase activity by acetylene reduction (Dart et al. 1972). After the acetylene reduction assay, the roots and nodules were cleaned of sand by washing in water and the nodules were separated and counted. The plant tops, roots, and nodules were dried at $70^{\circ} \mathrm{C}$ for $48 \mathrm{~h}$ and the dry weights were recorded. Plant samples were finely ground by a Cyclone mill (UDY Corporation, Colorado, USA) for various chemical analyses. The $\mathrm{N}$ and $\mathbf{P}$ contents of the plant material were determined by a block digestion method and a Technicon autoanalyzer (Industrial Method No: 218-72 A). For the determination of $\mathrm{Na}$, finely ground samples of $200-300 \mathrm{mg}$ were digested with $6 \mathrm{ml}$ tri-acid $\left(\mathrm{HNO}_{3}: \mathrm{H}_{2} \mathrm{SO}_{4}: \mathrm{HClO}_{4}\right.$ at $\left.10: 0.5: 2\right)$ in $50-\mathrm{ml}$ volumetric flasks in a sand bath at $250^{\circ} \mathrm{C}$ for $6-8 \mathrm{~h}$ (Piper 1952). The digested samples were diluted and analyzed by atomic absorption spectrophotometry (Varian, Model 1200). The chloride content in the plant samples was determined by Mohr's volumetric method (Blaedel and Meloche 1960).

\section{Results and discussion}

In all the Rhizobium sp. treatments, leaf area and shoot and root dry matter decreased with increasing salinity (Fig. 1). However, there were significant differ-

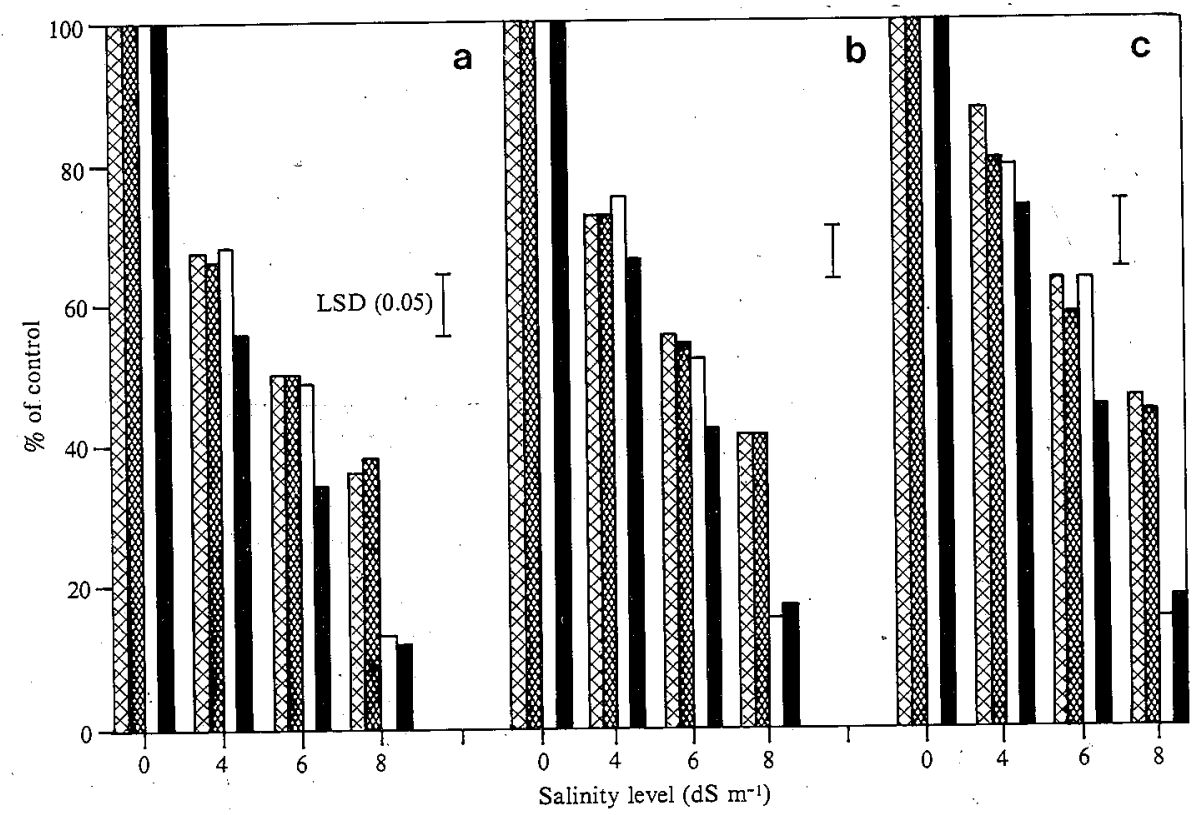

Fig. 1. Effect of salinity on a leaf area and $\mathbf{b}$ shoot and $\mathbf{c}$ root dry matter of pigeonpea genotype ICPL 227 inoculated with four Rhizobium strains. Data are means of four replications. $100 \%$ leaf area values 629 , $614,559,586\left(\mathrm{~cm}^{2}\right.$ pot $\left.^{-1}\right)$; shoot dry matter values $4.84,4.65,4.32,4.31$, and root dry-matter values $1.22,1.32$, 1.25 , and $1.23 \mathrm{~g} \mathrm{pot}^{-1}$ for IC 3087 (区), IC 3506 (团), IC 3195 ( $\square)$, and

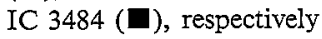


ences in the salinity response among Rhizobium sp. treatments. Rhizobium sp. IC 3484 and IC 3195 were more affected by salinity than IC 3087 and IC 3506 . This shows the variation among Rhizobium sp. strains in symbiotic ability with a common host under saline conditions.

For three of the Rhizobium sp. strains, the number. of nodules decreased with increasing salinity, and at $8 \mathrm{dS} \mathrm{m}^{-1}$. there was more than $90 \%$ reduction in the plants inoculated with IC 3484 and IC3195 (Fig. 2). In contrast, the number of nodules in plants inoculated with IC 3087 increased with increasing salinity. These results confirm that Rhizobium $\mathrm{sp}$. strains vary in their ability to nodulate under salinity stress. In several legumes, such as soybeans (Singleton and Bohlool 1984), pea (Siddiqui et al. 1985), cowpeas, mungbeans (Balasubramanian and Sinha 1976), and faba beans (Yousef and Sprent 1983), the total number of nodules was reported to decrease with increasing salinity. In soybeans, even $2.7 \mathrm{dS} \mathrm{m}^{-1}$ was able to suppress nodulation by $50 \%$ with nearly total suppression at $8.0 \mathrm{dS}$ $\mathrm{m}^{-1}$ (Singleton and Bohlool 1984), a response similar to that observed with IC 3484. There appears to be no published work indicating an increase in the number of nodules with increasing salinity for any Rhizobium sp. strain, as occurred for IC 3087 .

The total nodule dry matter decreased with increasing salinity in all Rhizobium sp. treatments (Fig. 2). However, the reduction with IC 3087 and IC 3506 was significantly less in comparison with IC 3484 and IC 3195. For IC 3506, IC 3195, and IC 3484, there was no significant change in the average nodule dry weight with increasing salinity (Table 2 ), and thus the de-.
Table 2. Effect of salinity on average nodule weight, specific nitrogenase activity, and leaf $\mathrm{N}$ and $\mathrm{P}$ of pigeonpea genotype ICPL 227 inoculated with different Rhizobium strains

\begin{tabular}{|c|c|c|c|c|}
\hline \multirow[t]{2}{*}{ Rhizobium strain } & \multicolumn{4}{|c|}{ Salinity level $\left(\mathrm{dS} \mathrm{m}^{-1}\right)$} \\
\hline & 0 & 4 & 6 & 8 \\
\hline \multicolumn{5}{|c|}{ Nodule weight (mg nodule ${ }^{-1}$ ) } \\
\hline IC 3087 & 0.57 & 0.33 & 0.31 & 0.28 \\
\hline IC 3506 & 3.12 & 2.89 & 3.60 & 3.16 \\
\hline IC 3195 & 1.88 & 1.74 & 1.82 & 2.20 \\
\hline IC 3484 & 2.78 & 2.53 & 3.65 & 2.07 \\
\hline \multicolumn{5}{|l|}{$\mathrm{LSD}$ at $5 \%=1.21$} \\
\hline \multicolumn{5}{|c|}{ Specific nitrogenase activity $\left(\mu \mathrm{mol} \mathrm{C}_{2} \mathrm{H}_{4} \mathrm{~g}^{-1}\right.$ dry nodule $\left.\mathrm{h}^{-1}\right)$} \\
\hline IC 3087 & 91.7 & 105.5 & 86.4 & 97.6 \\
\hline IC 3506 & 115.6 & 84.8 & 90.7 & 114.6 \\
\hline IC 3195 & 101.3 & 71.8 & 83.6 & 192.9 \\
\hline IC 3484 & 109.3 & 66.5 & 97.1 & 114.6 \\
\hline LSD at $5 \%=50.8$ & & & & \\
\hline \multicolumn{5}{|c|}{ Leaf $\mathrm{N}$ concentration ( $\mathrm{g} \mathrm{kg}^{-1}$ dry weight) } \\
\hline IC 3087 & 31.9 & 32.0 & 32.3 & 33.9 \\
\hline IC 3506 & 32.0 & 32.5 & 33.0 & $34: 9$ \\
\hline IC 3195 & 33.1 & 33.2 & 32.8 & 25.5 \\
\hline IC 3484 & 33.0 & 29.5 & 29.3 & 29.2 \\
\hline LSD at $5 \%=3.24$ & & & & \\
\hline \multicolumn{5}{|c|}{ Leaf $\mathrm{P}$ concentration ( $\mathrm{g} \mathrm{kg}^{-1}$ dry weight) } \\
\hline IC 3087 & 1.5 & 1.5 & 1.7 & 2.2 \\
\hline IC 3506 & 1.6 & 1.6 & 1.6 & 2.4 \\
\hline IC 3195 & 1.5 & 1.7 & 1.9 & 2.8 \\
\hline IC 3484 & 1.6 & 1.5 & 1.7 & 2.4 \\
\hline LSD at $5 \%=0.26$ & & & & \\
\hline
\end{tabular}

crease in the total nodule dry weight was merely a consequence of the reduced nodule number. This shows that nodule development is not affected by salinity, which is in agreement with the observations of Single-

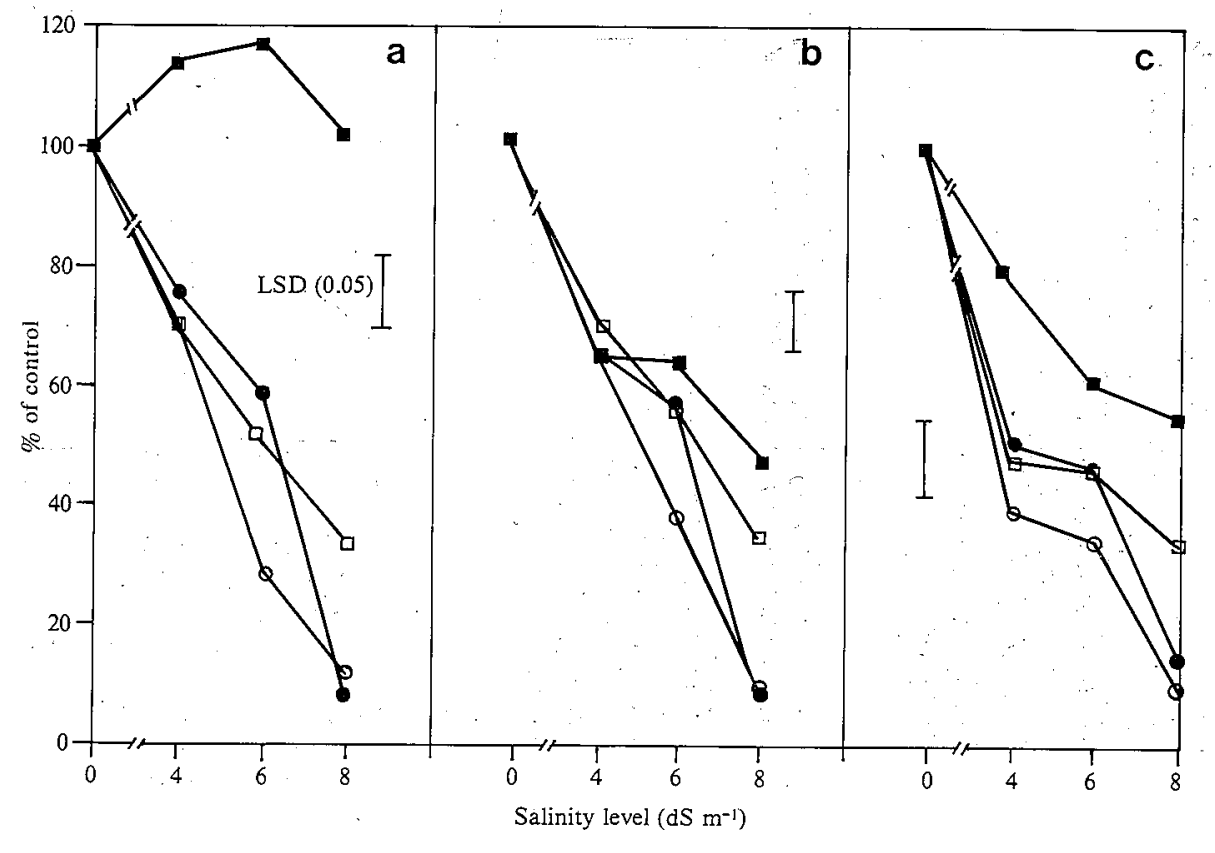

Fig. 2. Effect of salinity on a nodule number, $\mathbf{b}$ nodule dry matter, and c total nitrogenase activity of pigeonpea genotype ICPL 227 inoculated with four Rhizobium strains. Data are means of four replications. $100 \%$ nodule number $460,135,202$, $153\left(\right.$ pot $\left.^{-1}\right)$; nodule dry weight 261 , $400,379,419$ (mg pot $\left.^{-1}\right)$; nitrogenase activity $24.0,45.8,38.3$, and 45.0 $\left(\mu \mathrm{mol} \mathrm{C}_{2} \mathrm{H}_{4}\right.$ pot $^{-1} \mathrm{~h}^{-1}$ ) for IC 3087 $(\square)$, IC $3506(\square)$, IC $3195(\bullet)$, and IC 3484 (O), respectively 
ton and Bohlool (1984). However, with IC 3087, the average nodule dry weight was reduced to $50 \%$ of the control (non-saline) at $8 \mathrm{dS} \mathrm{m}^{-1}$, but this was not statistically significant due to the very.low average nodule weight even in the control, in comparison with the other Rhizobium sp. strains. This was the main reason for the decrease in the total nodule dry weight with this Rhizobium sp. treatment, even though the total number of nodules increased with increasing salinity. It is not known whether the apparent reduction in the average nodule dry weight with IC 3087 was due to a direct salinity effect on nodule development or an indirect effect of the reduced shoot growth at $8 \mathrm{dS} \mathrm{m}^{-1}$, causing a reduced supply of photosynthate to the symbiotic system.

The specific nitrogenase activity remained unaffected with increasing salinity in all the Rhizobium sp. treatments, except with IC 3195 at $8 \mathrm{dS} \mathrm{m}^{-1}$, where there was a significant increase which could have been caused by a severe reduction in the total nodule dry weight (Table 2). This shows that nodule functioning in general remained unaffected with salinity stress in all of the Rhizobium sp. treatments. The decrease in total nitrogenase activity with increasing salinity (Fig. 2) would therefore be due to the reduction in total nodule dry matter.

There was no significant change in the leaf- $\mathrm{N}$ concentration with increasing salinity with IC 3087 and IC 3506, whereas with IC 3484 and IC 3195 leaf-N levels decreased with increasing salinity (Table 2); howev-

Table 3. Effect of salinity on leaf, stem, and root Na concentrations in pigeonpea genotype ICPL 227 inoculated with different Rhizobium strains

\begin{tabular}{|c|c|c|c|c|}
\hline \multirow[t]{2}{*}{ Rhizobium strain } & \multicolumn{4}{|c|}{ Salinity level $\left(\mathrm{dS} \mathrm{m}^{-1}\right)$} \\
\hline & 0 & 4 & 6 & 8 \\
\hline \multicolumn{5}{|c|}{ Leaf $\mathrm{Na}$ concentration ( $\mathrm{g} \mathrm{kg}^{-1} \mathrm{dry}$ weight) } \\
\hline IC 3087 & 0.2 & 0.2 & 0.4 & 1.5 \\
\hline IC 3506 & 0.2 & 2.0 & 2.1 & 1.8 \\
\hline IC 3195 & 0.3 & 0.7 & 1.5 & 4.0 \\
\hline IC 3484 & 0.3 & 0.7 & 0.9 & 3.7 \\
\hline \multicolumn{5}{|l|}{$\mathrm{LSD}=0.94$} \\
\hline \multicolumn{5}{|c|}{ Stem $\mathrm{Na}$ concentration $\left(\mathrm{g} \mathrm{kg}^{-1}\right.$ dry weight) } \\
\hline IC 3087 & 0.4 & 1.2 & 1.2 & 2.9 \\
\hline IC 3506 & 0.4 & 1.7 & 1.7 & 1.9 \\
\hline IC 3195 & 0.4 & 1.3 & $=1.6$ & 5.5 \\
\hline IC 3484 & 0.4 & 1.2 & 2.8 & 7.0 \\
\hline $\mathrm{LSD}=0.95$ & & & & \\
\hline \multicolumn{5}{|c|}{ Root $\mathrm{Na}$ concentration ( $\mathrm{g} \mathrm{kg}^{-1}$ dry weight) } \\
\hline IC 3087 & 5.6 & 11.3 & 15.0 & 16.0 \\
\hline IC 3506 & 5.6 & 12.0 & 12.5 & 16.0 \\
\hline IC 3195 & 6.0 & 13.1 & 15.5 & 18.5 \\
\hline IC 3484 & 6.5 & 12.5 & 17.0 & 18.5 \\
\hline $\mathrm{LSD}=2.42$ & & & & \\
\hline
\end{tabular}

er the latter was significant only at $8 \mathrm{dS} \mathrm{m} \mathrm{m}^{-1}$. This shows that Rhizobium sp. IC 3484 and IC 3195, which gave severe reductions in nodulation and $\mathrm{N}_{2}$ fixation at $6 \mathrm{dS} \mathrm{m}^{-1}$ and above, were not able to maintain a $\mathrm{N}$ supply to the host under salinity stress, possibly leading to $\mathrm{N}$ deficiency. There was an increase in the leaf-P levels with increasing salinity (Table 2 ) in all the Rhizobium sp. treatments, suggesting that $\mathrm{P}$ uptake was not impaired by salinity. This is contrary to the findings of Wilson (1970) in soybeans, where P uptake was reported to be decreased with increasing salinity. $\mathrm{Na}$ and $\mathrm{Cl}$ levels in leaf, stem and roots of the pigeonpea increased with increasing salinity (Tables 3 and 4). There were no substantial differences among Rhizobium sp. treatments in this respect except at $8 \mathrm{dS}$ $\mathrm{m}^{-1}$, where shoot $\mathrm{Na}$ and $\mathrm{Cl}$ levels were significantly higher with IC 3195 and IC 3484 than with IC 3087 and IC 3506.

In previous studies, the selection of Rhizobium sp. strains for saline soils was made on the basis of the ability of strains to grow separately in saline yeast extract mannitol agar media (Yadav and Vyas 1971; Singleton et al. 1982). However, the salinity tolerance of free-living rhizobia is generally much higher than that of the host plant, and also, the tolerance of free-living Rhizobium sp. strains on yeast extract mannitol agar media does not correlate well with their symbiotic ability under saline conditions (Subbarao 1984; Table 1 and Fig. 1). The results of the present study have established that the variation in the growth of pigeonpea

Table 4. Effect of salinity on leaf, stem, and root $\mathrm{Cl}$ concentration of pigeonpea genotype ICPL 227 inoculated with different Rhizobium strains

\begin{tabular}{|c|c|c|c|c|}
\hline \multirow{2}{*}{ Rhizobium strain } & \multicolumn{4}{|c|}{ Salinity level $\left(\mathrm{dS} \mathrm{m}^{-1}\right)$} \\
\hline & 0 & 4 & 6 & 8 \\
\hline \multicolumn{5}{|c|}{ Leaf $\mathrm{Cl}$ concentration ( $\mathrm{g} \mathrm{kg}^{-1}$ dry weight) } \\
\hline IC 3087 & 0.7 & 12.7 & 26.2 & 40.5 \\
\hline IC 3506 & 0.7 & 13.1 & 26.2 & 36.4 \\
\hline IC 3195 & 0.7 & 12.6 & 27.0 & 44.4 \\
\hline IC 3484 & 0.7 & 13.0 & 32.3 & 44.0 \\
\hline $\mathrm{LSD}=1.89$ & & & & \\
\hline \multicolumn{5}{|c|}{ Stem $\mathrm{Cl}$ concentration ( $\mathrm{g} \mathrm{kg}^{-1}$ dry weight) } \\
\hline IC 3087 & 1.2 & 14.5 & 20.5 & 28.1 \\
\hline IC 3506 & 1.4 & 14.1 & 22.4 & 28.3 \\
\hline IC 3195 & 1.1 & 16.0 & 21.3 & 34.5 \\
\hline IC 3484 & 1.5 & 14.9 & 21.8 & 37.5 \\
\hline \multicolumn{5}{|l|}{$\mathrm{LSD}=2.36$} \\
\hline \multicolumn{5}{|c|}{ Root $\mathrm{Cl}$ concentration ( $\mathrm{g} \mathrm{kg}^{-1}$ dry weight) } \\
\hline IC 3087 & 6.0 & 22.0 & 24.0 & 24.0 \\
\hline IC 3506 & 6.0 & 22.5 & 21.5 & 22.5 \\
\hline IC 3195 & 6.0 & 21.0 & 22.0 & 25.0 \\
\hline IC 3484 & 7.0 & 19.5 & 22.5 & 26.5 \\
\hline \multicolumn{5}{|l|}{$\mathrm{LSD}=2.84$} \\
\hline
\end{tabular}


between the Rhizobium sp. treatments at different salinity levels was mainly due to the variation in their ability to form a symbiosis under saline conditions. This variation in symbiotic performance under saline conditions suggests that there is scope for the improvement of $\mathrm{N}_{2}$ fixation of pigeonpea in saline soils through the selection of rhizobia based on their symbiotic performance. Although one of the most efficient Rhizobium sp. strains, IC 3087, was collected from a saline soil, the other equally efficient strain, IC 3506 , was collected from a non-saline soil. This indicates that the Rhizobium sp. strains best able to form an effective symbiosis at high salinity levels are not necessarily derived from saline soils, as suggested by Bharadwaj (1975).

Acknowledgments. We are indebted to Dr D. L. Oswalt and Dr F. B. Lopez, ICRISAT, India, for their constructive criticism of the manuscript.

\section{References}

Balasubramanian V, Sinha SK (1976) Effect of salt stress on growth, nodulation and nitrogen fixation in cowpea and mungbeans. Physiol Plant 36:197-200

Bernstein L, Ogata G (1966) Effects of salinity on nodulation and nitrogen fixation and growth of soybeans and alfalfa. Agron J 58:201-203

Bharadwaj KKR (1975) Survival and symbiotic characteristics of Rhizobium in saline-alkali soils. Plant and Soil 43:377-385

Blaedel WJ, Meloche VW (1960) Elementary quantitative analysis. Harper and Row, New York
Chauhan YS (1987) Screening for tolerance to salinity and waterlogging, case studies with pigeonpea and chickpea. In: Saxena NP, Johansen C (Sci-Editors) Adaptation of chickpea and pigeonpea to abiotic stresses. Proc Consultant's Workshop, ICRISAT, 19-21 Dec 1984, India', pp 93-103

Dart PJ, Day JM, Harris D (1972) Assay of nitrogenase activity by acetylene reduction. In: Use of isotopes for study of fertilizer utilization by legume crops. IAEA/FAO, Vienna, Technical Booklet, pp $85-100$

Lakshmi-Kumari CS, Singh CS, Subbarao NS (1974) Root hair infection and nodulation in lucerne (Medicago sativa) as influenced by salinity and alkalinity. Plant and Soil 40:261-268

Lauter DJ, Munns DN, Clarkin KL (1.981) Salt response of chickpea as influenced by N supply. Agron J 73:961-966

Piper CS (1952) Soil and plant analysis. Hans Publishers, Bombay

Siddiqui S, Kumar S, Sharma HR (1985) Studies on the effects of salinization on nodulation and nitrogen fixation in pea (Pisum sativum). Indian J Plant Physiol 28:369-375

Singleton PW, Bohlool BB (1984) Effect of salinity on nodule formation by soybean. Plant Physiol 74:72-76

Singleton PW, El-Swaify SA, Bohlool BB (1982) Effect of salinity on Rhizobium growth and survival. Appl Environ Microbiol 44:884-890

Subbarao GV (1984) Comparative salinity tolerance of pigeonpea, its rhizobial strains and symbiosis. $M$ Tech Dissertation, Indian Institute of Technology, Kharagpur, India:

Vincent JM (1970) A manual for the practical study of the root nodule bacteria. Blackwell, Oxford

Wilson JR (1970) Response to salinity in Glycine: VI. Some effects of a range of short term salt stress on the growth, nodulation and nitrogen fixation of Glycine wightii. Aust" J Agric Res 21:571-582

Yadav NK, Vyas SR (1971) Response of root nodule rhizobia to saline-alkaline and acid conditions. Indian.J Agric Sci 41:875-881

Yousef AN, Sprent JI (1983) Effects of $\mathrm{NaCl}$ on growth, nitrogen incorporation and chemical composition of inoculated and $\mathrm{NH}_{4} \mathrm{NO}_{3}$ fertilized Vicia faba L. plants. J Exp Bot 34;941-950

Received June 11, 1989 